\title{
Biomedical experimentation with animals in europe: legal regulation and ethical aspects
}

\author{
Keywords: animals, test drugs, treatments, vertebrate, anthropoid \\ apes
}

\section{Commentary}

The use of animals in experimental research is nowadays essential. No computer model, or in vitro culture, can replace the experiments carried out with animals to test drugs or treatments. For that reason, for now we can only try to minimize the use of animals and reduce their suffering. Well, with this objective, a legal framework has been created in Europe, which, without expressly granting rights to animals, does establish obligations towards human beings. Specifically, two protection mechanisms coexist in Europe:

i. The first one is the European Convention for the Protection of Vertebrate Animals used for Experimental and Other Scientific Purposes, signed in Strasbourg on 18 March 1986, under the Council of Europe.

ii. The second, and more relevant, has been carried out within the scope of the European Union. Indeed, the EU has not only signed the Council of Europe Convention, but it has issued two directives that have been gradually improving the protection of certain animals when researching.

So, the EU has issued two directives, the Council Directive 86/609/ EEC of 24 November 1986, on the approximation of laws, regulations and administrative provisions of the Member States regarding the protection of animals used for experimental and other scientific purposes, and the Directive 2010/63/EU of the European Parliament and of the Council of 22 September 2010, on the protection of animal used for scientific purposes, that repeals the previous one. If we compare both protection systems, that of the Council of Europe (47 European countries), and that of the European Union, (27 countries after the "Brexit"), we can point out the following characteristics:

i. The Directive 63/2010 offers a degree of protection for animals far higher than that which was established in the 1986 Directive and in the European Convention itself.

ii. The European Convention protected only vertebrate animals, while Directive 63/2010 has extended the protection scope to other animals that may also suffer, such as cephalopods, ranking the degree of experimentation depending on the level of closeness, genetic or affective, to our species (anthropoid apes, rest of nonhuman primates, dogs and cats, etc.).

iii. The Directive 63/2010 clearly assigns the rule of the three "Rs", that is, the principles of replacement, reduction and refinement, something that was only slightly outlined in the European Convention. In addition, it has established a gradation in the animals, headed by the anthropoid apes, according to their ability to feel or suffer.

iv. Both sets of standards, conventions and directives, use euphemisms, such as "procedures" to refer to experiments on animals.
Volume 2 Issue 3 - 2018

\author{
Manuel Jesús López Baroni \\ Philosophy of law teacher, Universidad Pablo de Olavide, Sevilla, \\ Spain
}

Correspondence: Manuel Jesús López Baroni, Philosophy of law teacher, Universidad Pablo de Olavide, Sevilla, Carretera de Utrera s/n. Sevilla,Av. Diagonal 684, 08034 Barcelona, Spain, Tel 60950277I,Email mjlopbarl@upo.es

Received: May 02, 2018 | Published: June 18, 2018

v. The Directive 63/2010 develops a gradation of pain in animals, banning experiments when certain thresholds of suffering are reached.

vi. Theses increasing of the sensitivity about the suffering of animals explains that the European Union has dictated another type of norms that bear no relation whatsoever to biomedicine but to the commercialization of animal-derived products. Indeed, the EU has banned the marketing in all members states of cosmetics previously tested on animals through the Directive 2003/15 of 27 February 2003, on the approximation of the laws of the Member States relating to cosmetic products, that, after several postponements and not a few controversies, it came into full force ten years later. Following a similar logic, the Regulation (EC) 1007/2009 of the European Parliament and of the Council on Trade in Seal Products, banned the importation into the territory of the European Union of products derived from the seal arguing that they were sentient beings who may experience "pain, anguish, fear and other forms of suffering".

Finally, Regulation (EC) No 1523/2007 of the European Parliament and of the Council, of 11 December 2007, has also banned the marketing and importation from third countries, or export, of dog and cat skins and products that contain it. Although it can be improved, the analyzed framework is a good starting point in order one day, in a higher civilization, we will no longer depend on the animal kingdom. In fact, it is an objective explicitly established in Directive 63/2010. But that will be long term. The transition will be hard. Indeed, one of the paradoxes of new technologies is that they are expected to allow the definitive substitution of our animal dependence (for example, in nanotechnology, research aimed at eliminating the use of animals is prioritized). It may be thought that big data and artificial intelligence will allow us to process information on a large scale without having to resort to live experiments. However, the opposite is happening. Genetic engineering, in particular, has accentuated our dependence on animal models to be able to experiment before acting directly on human beings. And it is unthinkable to use carbon nanotubes in construction, in the case of nanotechnology, without first testing their effects on other mammals. 


\section{Conclusion}

In conclusion, building an ethical framework at the expense of certain suffering, during a phase of unknown duration, until we finally replace animals, is one of the great challenges of contemporary bioethics.

\section{Acknowledgement}

None.

\section{Conflict of interest}

The author declares no conflict of interest. 